Article

\title{
Life Cycle Assessment of a Commercially Available Organic Rankine Cycle Unit Coupled with a Biomass Boiler
}

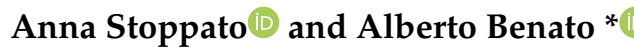 \\ Department of Industrial Engineering, University of Padova, 35131 Padova, Italy; anna.stoppato@unipd.it \\ * Correspondence: alberto.benato@unipd.it; Tel.: +39-049-827-6752
}

Received: 7 March 2020; Accepted: 4 April 2020; Published: 10 April 2020

check for updates

\begin{abstract}
Organic Rankine Cycle (ORC) turbogenerators are a well-established technology to recover from medium to ultra-low grade heat and generate electricity, or heat and work as cogenerative units. High firmness, good reliability and acceptable efficiency guarantee to ORCs a large range of applications: from waste heat recovery of industrial processes to the enhancement of heat generated by renewable resources like biomass, solar or geothermal. ORC unit coupled with biomass boiler is one of the most adopted arrangements. However, despite biomass renewability, it is mandatory to evaluate the environmental impact of systems composed by boilers and ORCs taking into account the entire life cycle. To this purpose, the authors perform a life cycle assessment of a commercially available $150 \mathrm{~kW}$ cogenerative ORC unit coupled with a biomass boiler to assess the global environmental performance. The system is modelled in SimaPro using different approaches. Results show that the most impacting processes in terms of $\mathrm{CO}_{2}$ equivalent emissions are the ones related to biomass production and organic fluid leakages with $71 \%$ and $19 \%$ of the total. Therefore, being fluid release in the environment high impacting, a comparison among three fluids is also performed. Analysis shows that adopting a hydrofluoroolefin fluid with a low global warming potential instead of the hydrocarbon fluid as already used in the cycle guarantees a significant improvement of the environmental performance.
\end{abstract}

Keywords: life cycle assessment; ORC; biomass; CHP; carbon footprint of energy production

\section{Introduction}

In 2018, despite the around $\$ 280$ Billion of global investment in renewable energy sources (RES) [1], global energy-related carbon dioxide $\left(\mathrm{CO}_{2}\right)$ emissions rose by 1.6\% [2]. An issue source of great concerns for people involved in the development of new and more eco-friendly energy scenarios.

In fact, at the time of writing, fossil fuels accounted for more than $85 \%$ in the coverage of the world primary energy consumption: 11,485 out of 13,511.2 Mtoe [1].

However, based on IRENA estimations [3], to meet the $2{ }^{\circ} \mathrm{C}$ climate goal, RES share in final energy consumption needs to rise from the $19 \%$ registered in 2017 , to $65 \%$ in 2050 . This means a constant and massive trend of growth for RES in the upcoming years.

Nevertheless, there would seem to be a need for general clarification. First of all, the analysis of 2018 available data [1], reveals an extremely interesting point: 70\% of new power additions were of renewable origin.

These RES installations were driven by the sky-rocket growth in terms of installed capacity of wind and solar: $+21 \%$ and $+47 \%$, respectively. A fact that pushed RES coverage of the world primary energy consumption over $10 \%$.

However, the growth in RES installations is not random; it is mainly driven by massive support actions. Indeed, starting from the year 2009, renewable energy sources are the subject of several 
European Union (EU) economic supports [4-6] because RES are considered the most promising way to reduce both primary energy consumption and $\mathrm{CO}_{2}$ emissions.

Thanks to these actions, EU primary energy consumption decreased from 1823.9 Mtoe to 1689.2 Mtoe in the period 2007-2017 while $\mathrm{CO}_{2}$ emissions drooped down of $9.4 \%$ in the period 2005-2016. These optimistic numbers confirm the effectiveness of these measures especially in view of a transition to RES based power generation systems characterized by massive electrification of transportation, buildings and industry.

Notwithstanding wind and solar eco-friendliness, the widespread availability and their undoubted considerable potential, it is important to remark that these sources are difficult to predict and exhibit large variation in space and time, characteristics which give rise to large unforeseeable power fluctuations. However, being electricity demand instantaneously balanced 24/7, huge and unpredictable power changes can be the source of imbalances between supply and demand that can provoke grid damage, user devices fault or blackouts. These unpleasant effects can be managed and/or limited using fossil fuels power plants working in cycling operation mode and energy storage units (see e.g., [7-17]).

Note that wind and solar variability and, consequently, unpredictability can be greatly affected by climate change because they are directly linked to climate variables like solar irradiation, wind, temperature and precipitation. So, being that the reliability and performance of RES plants are largely affected by climate conditions, it is also mandatory to consider climate change future impacts on meteorological conditions during the design of renewable-based energy systems. This approach can avoid mistakes during the design of energy infrastructures: systems characterized by high investment costs, long lifespan and a not negligible environmental impact.

Leaving aside concerns over climate change future impacts on RES based energy systems as well as solar and wind great potential and remarkable variability and unforeseeability, it is important to point out that there is a renewable source with great potential and a programmable production, able to generate heat, electricity or a combination of them, but first and foremost that largely contributes to gross final energy consumption and total primary energy supply. This RES is biomass.

Analyzing the latest data referred to the year 2016 [18], RES contribution to total primary energy supply is $14 \%$, of which about $70 \%$ from biomass ( $9.8 \%$ on the total primary energy), while it is $17.9 \%$ related to the gross final energy consumption of which about $73 \%$ from biomass (13\% on the total gross final energy).

Therefore, it is a matter of fact that biomass is a key source due to its widespread availability, production programmability and capability of generating electricity, heat or a combination of them.

Among RES, the electricity production coming from biomass ranks third after hydro and wind, while, for heat generation, biomass is the undisputed leader among renewables with about $96 \%$ of production.

A deeper look at biomass data [18] clearly shows that solid biomass with over $65 \%$ is the main contributor to electricity production, as well as of heat generation. This key role in both generation sectors is already visible for both developed and developing regions and can become crucial in the future to push the transition towards a decarbonized energy sector and a wider availability of energy.

Concerning electricity generation using biomass, several technologies are available according to the biomass type. As an example, liquid biofuels or biogas can be burnt in an Internal Combustion Engine (ICE) or in a Gas Turbine (GT) to generate electricity only or electricity and heat in Combined Heat and Power (CHP) units (see, e.g., [19-25]). In these cases, plant arrangements are really simple because the ICE and/or the GT, being their shaft mechanically coupled with the electric generator, directly produce electricity while heat is extracted from ICE coolant and lube oil or from the GT exhaust gases.

On the contrary, if solid biomass or municipal/industrial solid wastes are used as biofuel, the plant arrangement is more complex. 
In fact, when electricity is generated from solid biomass like woodchip, pellet, ect., plant architecture comprises a boiler in which the combustion process takes place and a Waste Heat Recovery Unit (WHRU) devoted to recovering the exhaust gases heat content and convert it into electricity or, if requires, into electricity and heat.

In literature, several WHRU types are available but the most adopted technologies are Steam Rankine Cycles-SRCs for large size units and Organic Rankine Cycles-ORCs for medium and low power unit (usually with an electric power lower than $2 \mathrm{MW}$ ).

Since the vast majority of applications is characterized by medium to low power, the conventional plant arrangement that adopts solid biomass as fuel is composed by a boiler and an ORC turbogenerator.

The organic Rankine cycle technology has been investigated since the years 1880, but its popularity increased only in the years 2000 with the growing interest in exploiting from medium to ultra-low grade heat sources. In fact, when the heat source temperature ranges from $80^{\circ} \mathrm{C}$ to $500{ }^{\circ} \mathrm{C}$, conventional steam Rankine cycle units fail for technical and economical reasons (see, e.g., [26-28]. Therefore, to recover the heat of these sources and convert it into useful electrical energy or electricity and heat, the ORC technology is the most efficient option.

An ORC operates in the same way as a steam Rankine cycle but an organic compound (hydrocarbons, hydrofluorocarbons, hydro-chlorofluorocarbons, chlorofluorocarbons, per-fluorocarbons, siloxanes, alcohols, aldehydes, ethers hydrofluoroethers, amines, zeotropic and azeotropic mixtures) is used as working fluid instead of water.

Due to the availability of a large number of possible working fluids and several plant schemes (basic, regerative, recuperative and regenerative, etc. and with or without intermediate oil or water loop—for more details see, e.g., [27]), the ORC unit design is a complicated task.

For this reason, thousands of researches have been conducted around the world with the aim of selecting the best working fluid and plant configuration for a wide range of sources as well as optimizing and testing plant or its components (see, e.g., [29-37]). There are also works devoted to environmental and exergetic assessment of power generation units.

However, despite the large variety of published works, there is a lack of studies aiming to quantify the environmental impact of an in-operation organic Rankine cycle power plant coupled with a biomass boiler. To perform this kind of investigation, the Life Cycle Assessment (LCA) approach needs to be adopted.

In a nutshell, Life Cycle Assessment is today one of the most accredited assessment methods at the international level for the quantification of damage and its outcomes because these can be immediately correlated to impacts on human health, quality of ecosystems and consumption of natural resources [38].

The life cycle analysis allows to go beyond the geographical boundaries of the plant and to assess the impacts throughout the "value chain", such as those associated with emissions due to the entire biomass supply chain as well as construction, operation and decommissioning phases of plants.

Note that, Life Cycle Assessment has already been applied to biomass power generation unit or ORC. As an example, Stougie et al. [39] performed an environmental and exergetic sustainability assessment of different plants using biomass. Bioethanol from verge grass and biogas from manure are considered as fuel. Results are focused on the effects of different allocations strategies and underline that the environmental sustainability depends on the way of dealing with by-products.

With respect to the life cycle assessment of ORCs, researchers mainly focus on environmental benefits coming from the installation of ORC units in energy-intensive processes or in RES installations. As an example, Walsh and Thornley [40] evaluated the environmental impact and economic feasibility of introducing an organic Rankine cycle to recover low-grade heat during the production of metallurgical coke. Results show that an ORC can compensate from 1 to $3 \%$ of the $\mathrm{CO}_{2}$ directly emitted during the coke production. This means a yearly reduction of $10,000 \mathrm{t} \mathrm{CO}_{2}$. In addition, the electricity generated by the ORC replaces all the industry imported electricity. This fact contributes to compute a relatively attractive pay-back period: less than six years. Based on these findings, 
the authors concluded that ORC can be considered a cost-effective method of achieving Greenhouse Gas (GHG) savings in process industries.

Liu et al. [41] investigated the environmental impact of an organic Rankine cycle power plant for waste heat recovery. The considered heat source temperature and mass flow are $423.15 \mathrm{~K}$ and $1 \mathrm{~kg} / \mathrm{s}$, respectively, while seven possible working fluids are tested. Results exhibit that the ORC operating with R113 allows the lowest environment impact load followed by the one working with Pentane.

Heberle et al. [42] performed an LCA of organic Rankine cycles for geothermal power generation considering low-GWP working fluids. In particular, the analysis focuses on organic fluids' environmental impact and, specifically, on the impact linked to fluid losses. Results underline that substituting R245fa and R134a with R1233zd, R1234yf or natural hydrocarbons guarantees to significantly reduce the environmental impact. In addition, adopting a two-stage ORC configuration operating with R1233zd instead of a subcritical one-stage system working with R245fa leads to $2 \%$ higher exergetic efficiency and a reduction of the global warming impact from $78 \mathrm{~g} \mathrm{CO}_{2} / \mathrm{kWh}$ to $13 \mathrm{~g} \mathrm{CO}_{2} / \mathrm{kWh}$.

Lin et al. [43] used the LCA to evaluate the benefit on environmental impacts introduced by the use of an ORC and wood pellet fuel in the electric arc furnace steel industry. Results reveal that the environmental impacts on ecosystems, human health and resource depletion can be mitigated by adopting the ORC and replacing the heavy oil with wood pellets.

Uusitalo et al. [44] investigated the possibility of reducing GHG emission of biogas engine by the generation of additional electricity from the recovery of waste heat. ORC is the selected WHRU and two scenarios are compared: (i) the ICE generates only electricity and the produced heat is considered a loss, (ii) the exhaust heat from the biogas engine is used as a heat source to generate additional electricity via the ORC technology. LCA reveals that the ORC technology guarantees to reduce the annual GHG emission of at least $280 \mathrm{tCO}_{2, \text { eq }}$. So, ORCs can reduce GHG emissions and increase renewable electricity production from biogas engines.

Sedpho et al. [45] performed a conventional and exergetic life cycle assessment on an organic Rankine cycle mounted on a to municipal waste management facility. The selected case study is Mae Hong Son province in Thailand. LCA results highlight that the environmental impact and the energy consumption can be reduced by applying the waste treatment technology of the Refuse-Derived Fuel and a $20 \mathrm{~kW}$ organic Rankine cycle unit.

Obviously, several other works dealing with LCA analysis of pellet boilers (e.g., [46]), renewable and fossil fuels (e.g., [47,48]), photovoltaic panels (e.g., [49]), conventional and near-zero energy buildings (e.g., [50]), concert (e.g., [51]), etc. are available in literature. However, as said, to the authors' knowledge, no one has previously presented an investigation devoted to analyzing with the LCA approach a commercially available biomass boiler coupled with a $150 \mathrm{~kW}$ cogenerative ORC unit with the aim of understating the system environmental impacts. Being the boiler fed by woodchip, the entire production pathway, starting from wood cultivation, is considered as well as the ORC unit fluid losses along its lifespan. In this regard, in the analysis, three working fluids are tested with the aim of assessing the less impacting one but still maintaining the ORC performance.

The rest of the paper is organized as follows. Section 2 presents the case study and the model setting while in Section 3 materials and methods are described. Section 4 reports the LCA outcomes while in Section 5 conclusion remarks are given.

\section{Case Study and Model Settings}

The analysis is performed considering a real in-operation system located in the Northeast of Italy. The plant is powered by woodchip of which about $40 \%$ is made of birch, $24 \%$ of spruce, $20 \%$ of pine, $14 \%$ of beech and $2 \%$ of oak wood. Woodchip lower heating value on dry mass is $18.9 \mathrm{MJ} / \mathrm{kg}$. The timber comes from dedicated woods grown within a radius of $75 \mathrm{~km}$ from the plant while its transportation is done by means of freight lorry. 
The ORC module, whose main features are summarized in Table 1, is a commercially available Combined Heat and Power unit adopting as working medium a mixture of hydrocarbons (for simplicity the fluid is named "HCF") with a Global Warming Potential (GWP) equal to 950 and an Ozone Depletion Potential (ODP) equal to 0.

The ORC works with a regenerative sub-critical cycle where the useful heat is delivered as hot water at about $80^{\circ} \mathrm{C}$.

A schematic view of the system and its main devices is given in Figure 1 and Table 2.

Table 1. Main features of the Organic Rankine Cycle (ORC) module at design conditions.

\begin{tabular}{|c|c|c|c|}
\hline Parameters & Unit & Full Electric Mode & CHP Mode \\
\hline Input thermal power & $\mathrm{kW}$ & 1100 & \\
\hline Inlet temperature of the heat transfer fluid (water) & ${ }^{\circ} \mathrm{C}$ & $\geq 160$ & \\
\hline Outlet temperature of the heat transfer fluid (water) & ${ }^{\circ} \mathrm{C}$ & 140 & \\
\hline Heat transfer fluid (water) mass flow rate & $\mathrm{kg} / \mathrm{s}$ & 13.14 & \\
\hline Electric power & $\mathrm{kW}$ & 150 & 98 \\
\hline Electric efficiency & $\%$ & 13.6 & 8.6 \\
\hline Output thermal power & $\mathrm{kW}$ & 940 & 1000 \\
\hline Inlet temperature of water for thermal use & ${ }^{\circ} \mathrm{C}$ & 26 & 60 \\
\hline Outlet temperature of water for thermal use & ${ }^{\circ} \mathrm{C}$ & 36 & 80 \\
\hline Water mass flow rate & $\mathrm{kg} / \mathrm{s}$ & 22.46 & 11.95 \\
\hline
\end{tabular}

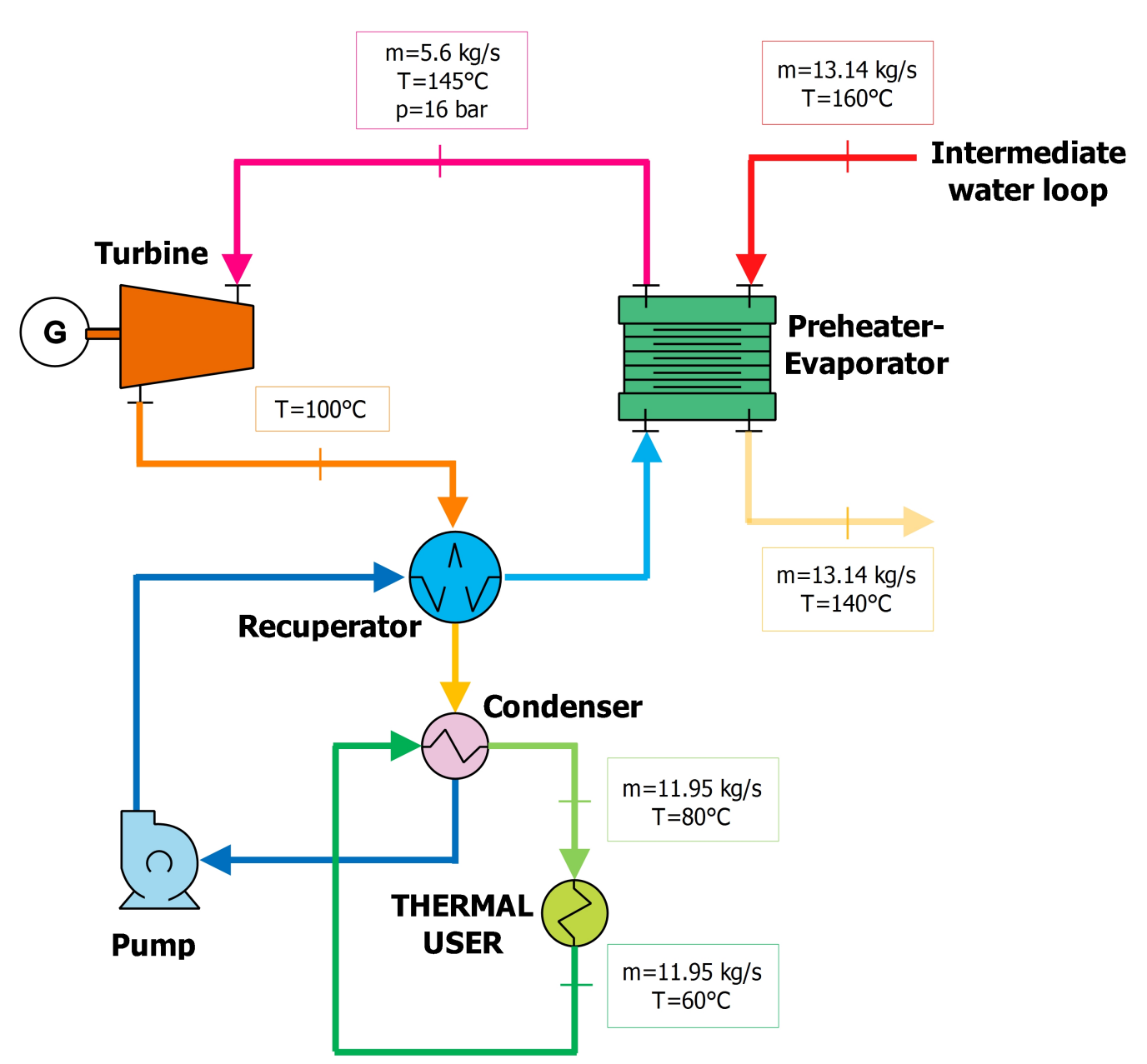

Figure 1. Schematic view of the ORC unit in its Combined Heat and Power (CHP) operation. Data refer to design point operating conditions. 
Table 2. Devices of the ORC module.

\begin{tabular}{ll}
\hline Components & Characteristics \\
\hline Pre-heater & Counter-flow brazed plate heat exchanger \\
Evaporator & Counter-flow brazed plate heat exchanger \\
Turbine & Radial turbine with fixed nozzles \\
Electric generator & Brushless synchronous generator with permanent magnets \\
Regenerative heat exchanger & Counter-flow brazed plate heat exchanger \\
Condenser & Counter-flow brazed plate heat exchanger \\
Pump & Centrifugal machine \\
\hline
\end{tabular}

To avoid risky contact between biomass combustion products and the ORC working fluid and to guarantee a steadier operation, the manufacturer adopts an intermediate water loop.

Thanks to this arrangement, biomass can be directly burnt in a commercial boiler.

The combustion products generated from biomass combustion heat up the pressurized water flowing in the intermediate loop, which in turn exchanges heat with the organic fluid.

The system includes also a cooling tower which allows to operate in full electric mode when users do not require heat.

In order to perform the Life Cycle Assessment analysis, data collected during five years of plant operation and from manufactures datasheets are organized in accordance with the provisions of ISO 14040 [38].

The system model is implemented in SimaPro environment [52].

SimaPro is one of the leading LCA software packages; it is a tool for the collection, analysis and monitoring of data on the environmental performance of goods and services. It makes available many internationally recognized sectoral databases, which allow the insertion of data and processes into inputs and outputs and includes the most recognized impact analysis methods.

In the system's model, data related to ORC devices are considered: weights, type of materials and mechanical processing.

Table 3 summarizes the materials used to build the ORC system. They comprise weights of pipes, valves, tank of the condensate, cooling tower, inverter, electrical cabinet and skid. For simplicity, materials are grouped for families, but in the inventory, the specific materials are considered. As an example, Table 3 lists steel, but in the inventory, carbon and stainless steel are separately accounted for.

Table 3. Summary of the mass streams of the ORC module.

\begin{tabular}{lll}
\hline Material & Unit & Weight \\
\hline Steel & $\mathrm{kg}$ & 5320 \\
Brass & $\mathrm{kg}$ & 25 \\
Pig iron & $\mathrm{kg}$ & 150 \\
Copper & $\mathrm{kg}$ & 510 \\
Aluminium alloy & $\mathrm{kg}$ & 2 \\
Permanent magnets & $\mathrm{kg}$ & 4.32 \\
\hline
\end{tabular}

The processes of braze welding in the heat exchangers, the anti-rust treatment of the tank, the welding of the pipes and the heat galvanization treatment of the cooling tower are also included in the analysis as well as the transport of all the devices to the plant installation site.

As known, in ORC plant the working fluid is an organic compound. The under investigation ORC unit adopts as working fluid a mixture of hydrocarbons (previously named "HCF") and it requires about $362 \mathrm{~kg}$ of fluid.

From data collected during the five years of operation, it is possible to estimate both leakage of organic fluid in the environment and cooling tower refill water. Organic fluid leakage is expected to be about $2 \%$ /year, while the estimated cooling tower water refilling is approximately $26.4 \mathrm{~kg} / \mathrm{min}$. 
Based on plant manufacturer experience in terms of both components lifespan and maintenance activities, a plant life equal to 15 years can be assumed.

Concerning the end of life scenario, it is expected that about $80 \%$ of the organic fluid is recovered at the end of plant life, while the remaining $20 \%$ is considered to be released in the environment [53].

Starting from the Italian recycling rates of steel and copper $[54,55]$, it is reasonable to assume a recycling percentage for steel and copper equal to $70 \%$ and $90 \%$, respectively. It is also assumed that non-recycled materials are sent to landfills.

\section{Materials and Methods}

The functional unit is $1 \mathrm{kWh}$ of electricity production.

Two different operating conditions are investigated:

- Plant working in full electric mode for $6000 \mathrm{~h} /$ year. This operating condition corresponds to a production during the entire life of the plant of 13,500 MWh.

- Plant running in CHP mode for $3000 \mathrm{~h} /$ year while, for the remainder $3000 \mathrm{~h} /$ year, it works in full electric mode. Note that, this is a regular working condition for plants serving residential users, as in the under-investigation case. It corresponds to an electricity production during the entire life of the plant of 11,160 MWh, and a heat production of 33,750 MWh.

In both cases, the overall biomass consumption is 99,000 MWh.

These data are added to the model with those related to plant construction and end of life, and to those associated to biomass cultivation and transport discussed in the previous section.

Figure 2 depicts a simplified tree representation of the ORC system implemented model.

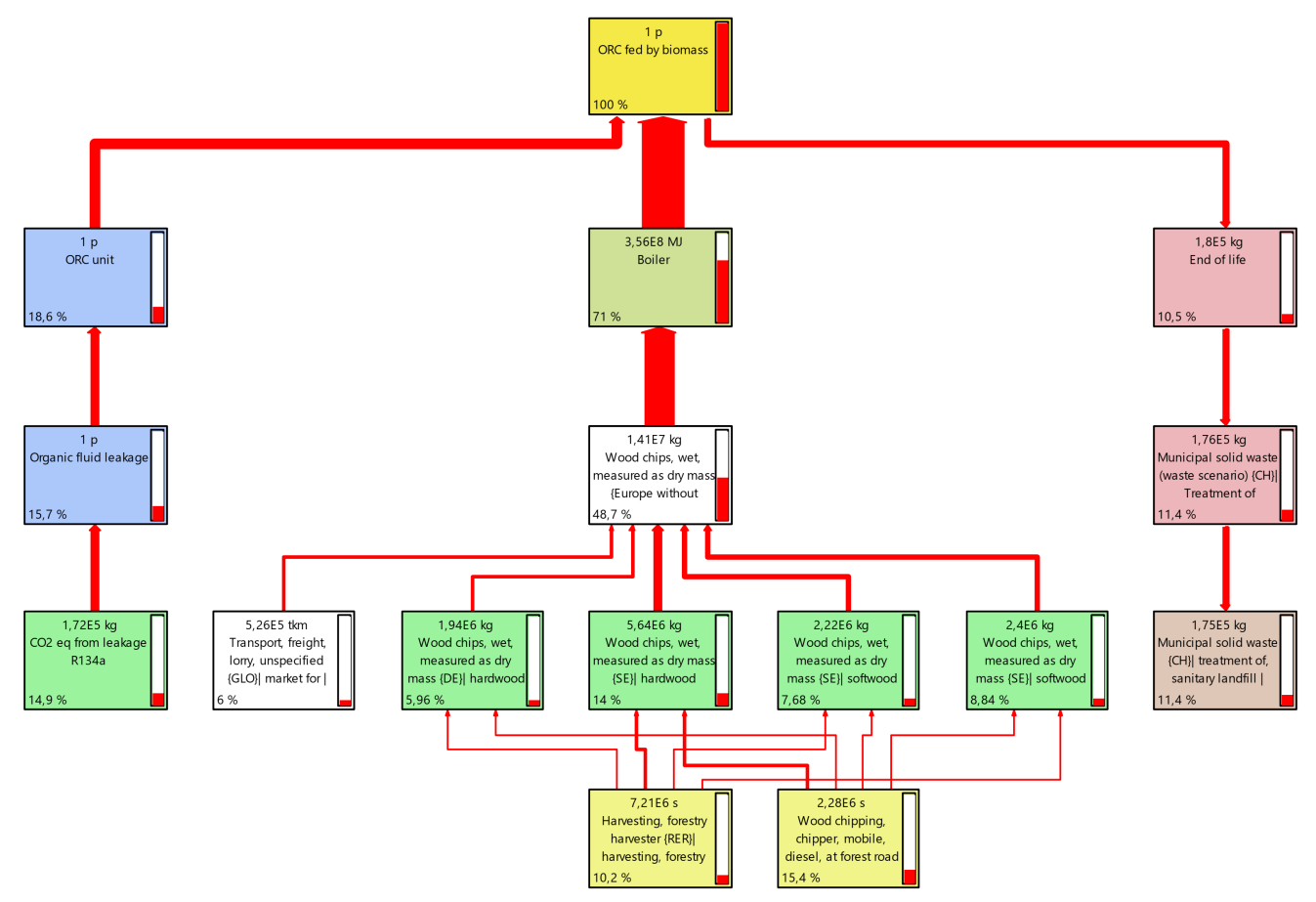

Figure 2. Simplified tree representation of the system in the lifecycle assessment. Percentages and lines refer to $\mathrm{CO}_{2, \text { eq }}$ emissions.

As stated above, the commercial software SimaPro 9.0 [52] is used to build the ORC system model and to perform the Life Cycle Assessment analysis.

Among the different databases implemented in the software, Ecoinvent 3, Agri-footprint, USA Input-Output Database, EU and DK Input-Output Database, LCA Food DK are employed to study 
the processes of production, transport and disposal of each material constituting the plant. For electricity consumed during the construction and end of life phases, the Italian low voltage market mix is considered.

For impacts evaluation, the model implements four different methods:

- IPCC 2013 GWP100y [56], developed by the IPCC with a unique focus on the greenhouse effect. In this work, the analysis refers to the factors over 100 years, which quantify the medium-term effects of emissions.

- ReCiPe 2016, whose primary goal is transforming the long list of inventory results into a small number of significant indicators [57] but sufficient to describe the total effects of the process under examination on the environment. Here, the Hierarchical Perspective $(\mathrm{H})$ is used, as suggested in [52], with "European" standardization and "medium" weighing set. Both Midpoint and Endpoint Indicators are computed.

- Cumulative Energy Demand, a method with a unique focus on the energy demand [58].

- Greenhouse Gas protocol [59], developed by the World Resources Institute and the World Business Council for Sustainable Development, with a unique focus on the carbon footprint. It considers also biogenic and untaken emissions.

\section{Results and Discussion}

Table 4 summarises the impacts computed with the ReCiPe 2016 method for the operation at full electric load, while Figure 3 depicts the contribution of the different operations on the overall impact.

Table 4. Summary of the mass stream of the ORC module.

\begin{tabular}{|c|c|c|}
\hline Impact Category & Unit & Total \\
\hline Global warming & $\mathrm{kg} \mathrm{CO} 2$,eq & 0.085283 \\
\hline Stratospheric ozone depletion & $\mathrm{kg} \mathrm{CFC} 11_{\mathrm{eq}}$ & $5.53 \times 10^{-7}$ \\
\hline Ionizing radiation & $\mathrm{kBq}$ Co- $60_{\mathrm{eq}}$ & 0.001301 \\
\hline Ozone formation. Human health & $\mathrm{kg} \mathrm{NO}$ x,eq & 0.001811 \\
\hline Fine particulate matter formation & $\mathrm{kg}$ PM2.5 $5_{\mathrm{eq}}$ & 0.000439 \\
\hline Ozone formation. Terrestrial ecosystems & $\mathrm{kg} \mathrm{NO}_{\mathrm{x}, \mathrm{eq}}$ & 0.00184 \\
\hline Terrestrial acidification & $\mathrm{kg} \mathrm{SO}_{2, \mathrm{eq}}$ & 0.001447 \\
\hline Freshwater eutrophication & $\mathrm{kg} \mathrm{P}$ eq & $5.83 \times 10^{-6}$ \\
\hline Marine eutrophication & $\mathrm{kg} \mathrm{N} \mathrm{N}_{\text {eq }}$ & $8.33 \times 10^{-6}$ \\
\hline Terrestrial ecotoxicity & kg 1.4-DCB & 1.68345 \\
\hline Freshwater ecotoxicity & $\mathrm{kg} 1.4-\mathrm{DCB}$ & 0.007768 \\
\hline Marine ecotoxicity & kg 1.4-DCB & 0.01133 \\
\hline Human carcinogenic toxicity & kg 1.4-DCB & 0.002995 \\
\hline Human non-carcinogenic toxicity & kg 1.4-DCB & 0.510964 \\
\hline Land use & $\mathrm{m}^{2} \mathrm{a}$ cropeq & 0.87156 \\
\hline Mineral resource scarcity & $\mathrm{kgCu}$ eq & 0.000275 \\
\hline Fossil resource scarcity & kg oileq & 0.015262 \\
\hline Water consumption & $\mathrm{m}^{3}$ & 0.009958 \\
\hline
\end{tabular}

Focusing on global warming, total emissions of climate-changing gases are equal to $85.2 \mathrm{~g}$ $\mathrm{CO}_{2, \mathrm{eq}} / \mathrm{kWh}$; a value definitively lower than that of the production from fossil fuels, which is estimated around $500 \mathrm{~g} \mathrm{CO}_{2, \mathrm{eq}} / \mathrm{kWh}$ for the Italian fossil mix [60].

Note that the organic fluid leakages in the ORC affects this value for about $18.6 \%$. Then, greater attention needs to be paid to this aspect because a better management of the leakages can remarkably improve the impact.

The recycling of steel and copper gives an appreciable positive impact on the mineral resource scarcity and Freshwater Eutrophication.

A large amount of water is required; but, for about $98 \%$ it is computable to the water evaporation in the cooling tower. 
For many categories, biomass constitutes the major impact. This fact is related to the transportation of wood and tinder, while combustion is responsible for ODP and ecotoxicity high values due to the release of particulate emissions and ash.

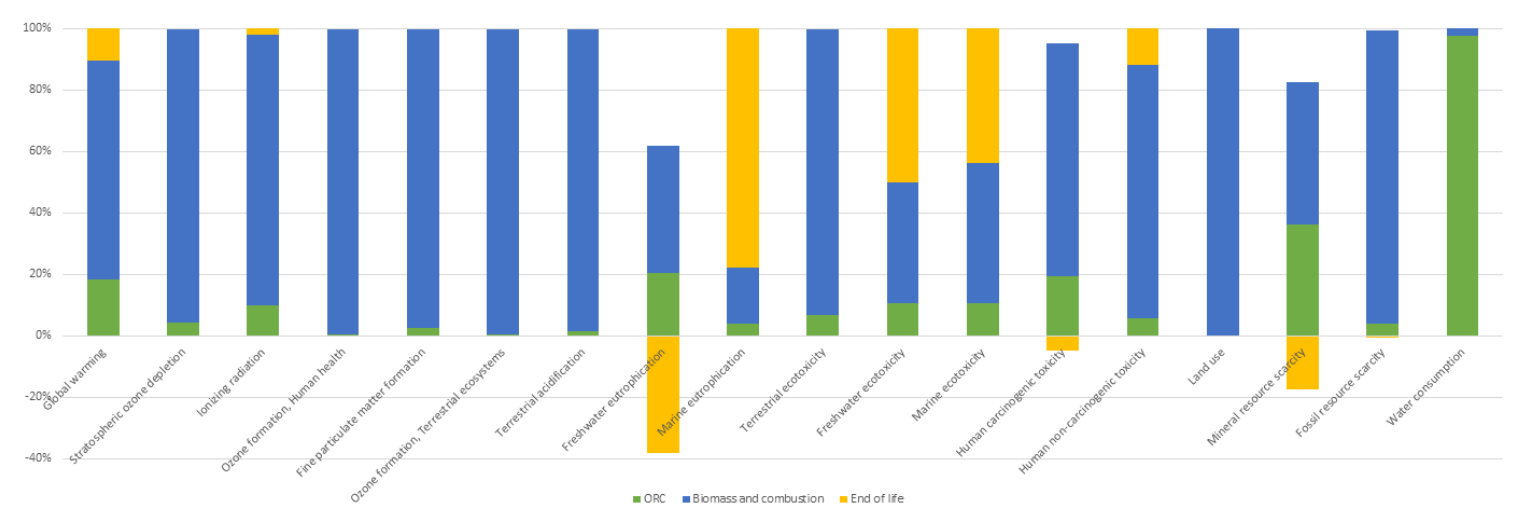

Figure 3. Contribution of operations in full electric mode (ReCiPe 2016 method).

Figure 4 summarizes the results of the ReCiPe Endpoint $(\mathrm{H})$ method and shows the shares of different impacts on Human Health. It is clear that the emissions of particulate matter are the most impacting factor, followed by the non-carcinogenic and climate change emissions. All these emissions are mainly related to the combustion of biomass, and secondarily to the ash management.

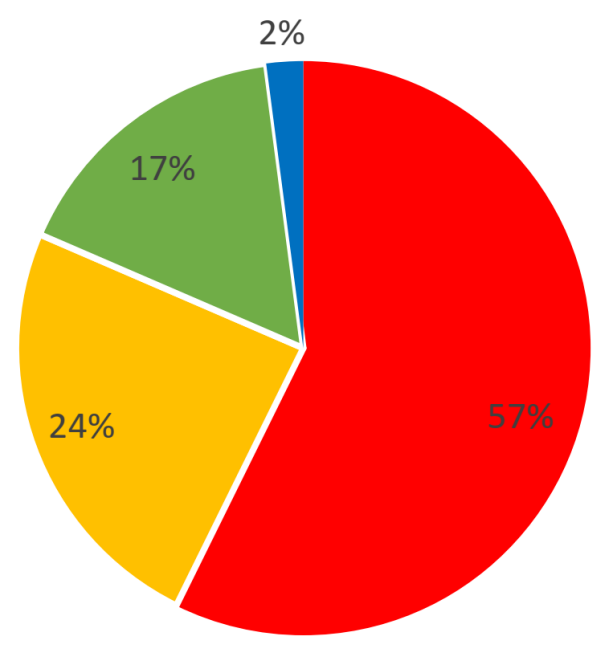

- Fine particulate matter formation DALY $=$ Human non-carcinogenic toxicity DALY

- Global warming. Human health DALY Guman carcinogenic toxicity DALY

Figure 4. Contribution to Human Health of different impacts. Results are obtained with ReCiPe 2016-Endpoint $(\mathrm{H})$ method.

Similar results are obtained in [61], where emissions related to the combustion and the transport process of the biomass have the largest share on overall plant impact.

The shares of different impacts on the ecosystem are reported in Figure 5. In this case, the land consumption linked to biomass cultivation is absolutely the most important factor.

In the case of managing the ORC in CHP mode, the avoided use of domestic boilers needs to be considered in the LCA analysis. Then, as shown in Figure 6, it is clear that managing the unit in CHP mode helps to reduce the overall impact. For many impact categories, the contribution of the ORC 
system becomes negative because the benefit introduced by the avoided use of natural gas in domestic boilers is higher than the impact generated by the ORC plant.

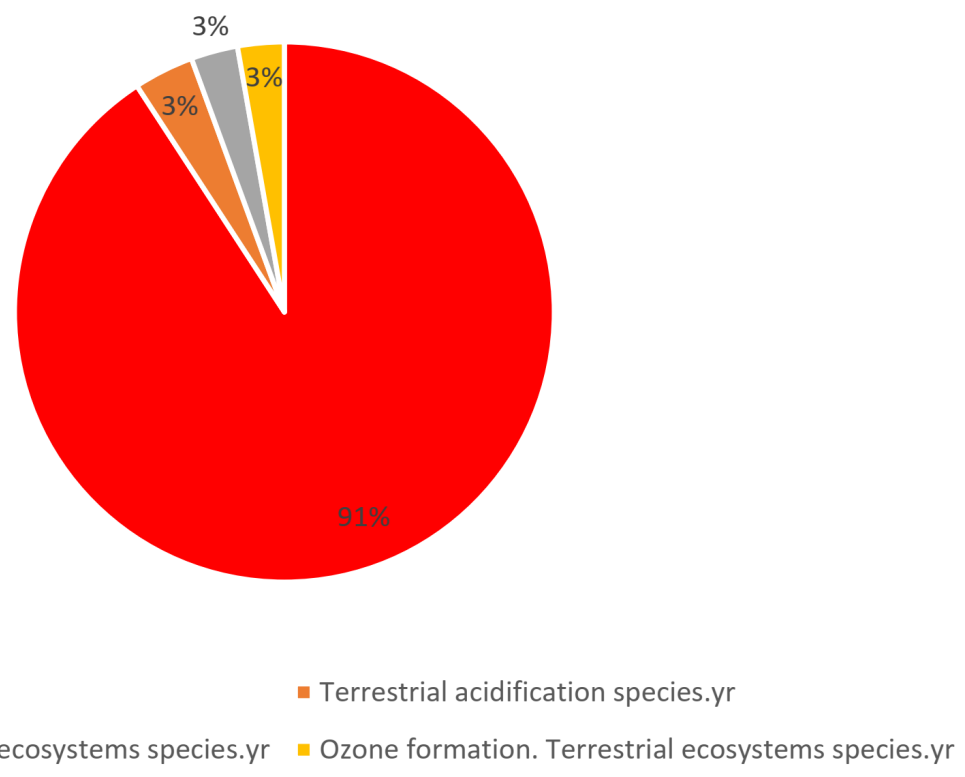

$\begin{array}{ll}\text { - Land use species.yr } & \text { - Terrestrial acidification species.yr } \\ \text { - Global warming. Terrestrial ecosystems species.yr } & \text { " Ozone formation. Terrestrial ecosystems species.yr }\end{array}$

Figure 5. Contribution to Ecosystem of different impacts. Results are obtained with ReCiPe 2016-Endpoint $(\mathrm{H})$ method.

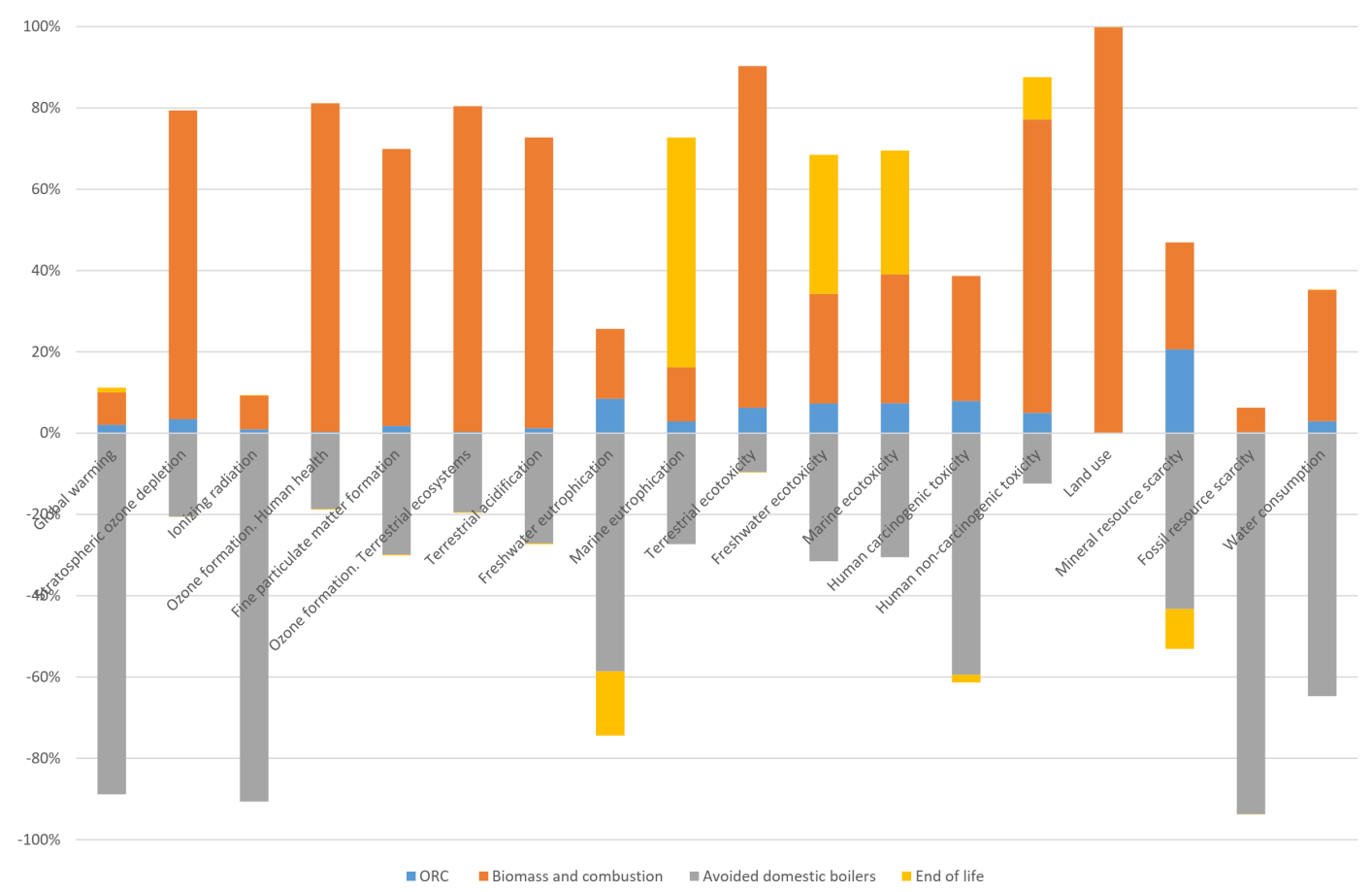

Figure 6. Contribution of the different operations to the overall impact in CHP mode. Results are obtained with ReCiPe 2016-Midpoint (H) method.

Figure 7 presents a focus on the ORC unit since it does not consider the biomass cultivation and combustion. In particular, the contribution of each device constituting the ORC unit is highlighted. It is clear that the need of an organic fluid is the source of high impact for two categories: Climate Change and Ozone Depletion, while the skid, the regenerator and the condenser exhibit a high-impact on a large number of categories due to the involvement of high mass of materials used to build these components. 


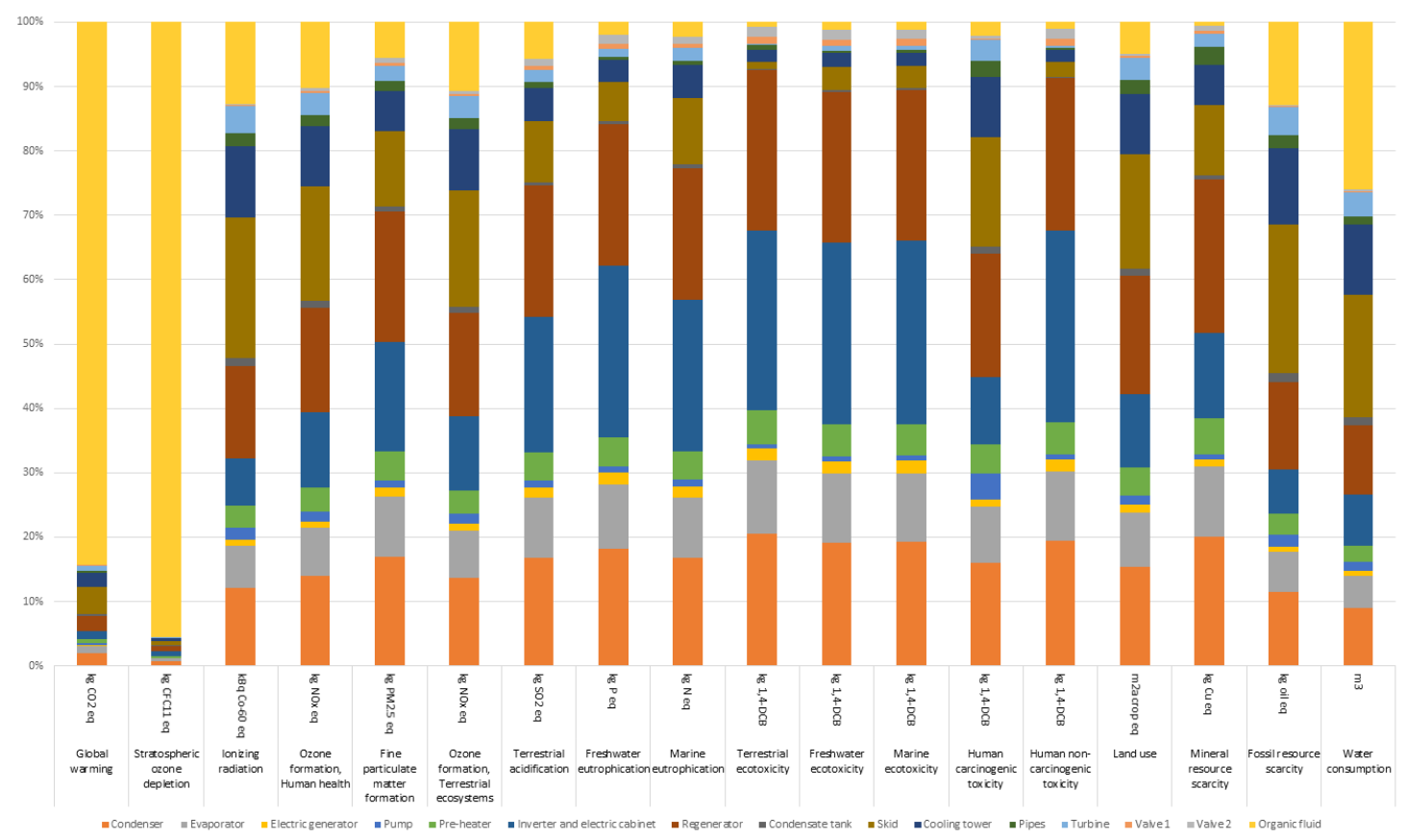

Figure 7. Contribution on the different impact categories of ORC devices construction and operation. Results are obtained with ReCiPe 2016-Midpoint (H) method.

Focusing on carbon footprint (see Figure 8 and Table 5), the impact of the combustion is clearly predominant as regards the biogenic carbon dioxide equivalent emitted, but biomass has a large impact also as regards to the emission of fossil carbon dioxide, which is of greater interest. Although the contribution of this phase is still prevalent, it accounts only for $79 \% ; 21 \%$ of the emissions are instead determined by the production, assembly, disposal of the ORC module and by the discharge of part of the organic fluid into the atmosphere.

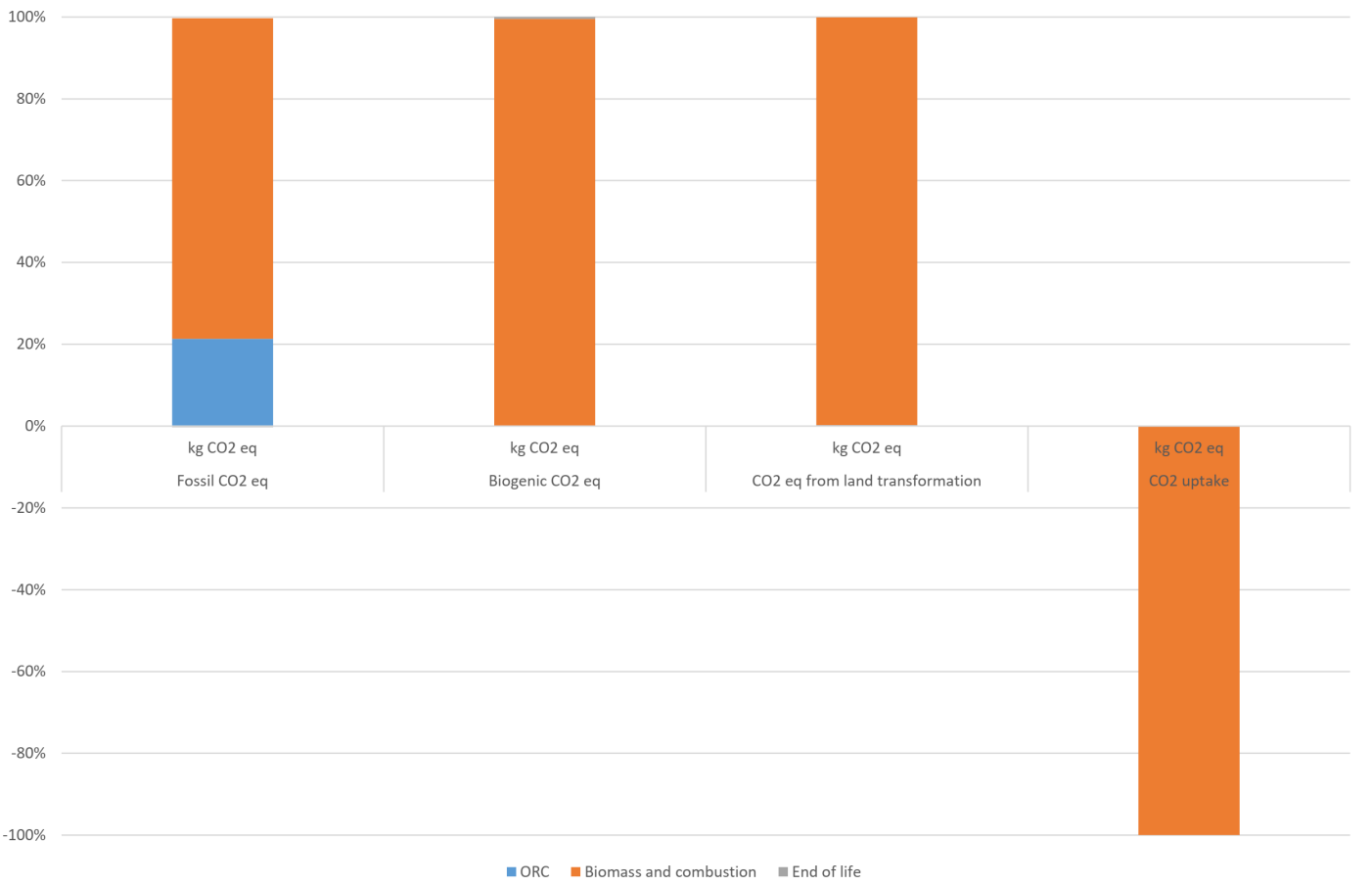

Figure 8. Carbon footprint. 
Table 5. Summary of the carbon footprint.

\begin{tabular}{ll}
\hline Impact Category & $\mathbf{g ~ C O}_{2, \mathbf{e q}}$ \\
\hline Fossil & 73.2 \\
Biogenic & 1910 \\
from land transformation & 0.89 \\
$\mathrm{CO}_{2}$ uptake & 1900 \\
\hline
\end{tabular}

For a full grasp of these specific simulation outcomes, it is important to underline that "biomass and combustion" component includes, besides combustion, the phase of cultivation, processing and transport of biomass, boiler construction and use of pollutant abatement systems.

In order to evaluate the possibility of improving the life cycle performances of the system, as suggested by other researchers (see, e.g., [41]), the LCA analysis needs to be performed adopting also different organic fluids. In this analysis, R245fa and R1233zd are selected and their behavior compared to the "HCF" fluid originally used in the ORC unit.

Both fluids are characterized by an ODP equal to 0 as in the case of "HCF". The GWP amounts to 1030 in the case of R245fa (8.4\% higher than the one of the actually adopted fluid) while it is equal to 1 for R1233zd (950 times lower than the "HCF" one). R1233zd is a low GWP fluid design to substitute R123 but it still constitutes a valid replacement to R245fa. A preliminary simulation of the ORC permits to evaluate the efficiency of the cycle with the new fluids and their required amounts.

Figure 9 summarizes the results obtained with the ReCiPe 2016 method. It is clear that for some categories, such as climate change and ecotoxicity, the impact using R1233zd is really reduced. Thus, this fluid guarantees the same energetic performance of the "HCF" but an absolutely lower impact on the entire set of impacts categories.

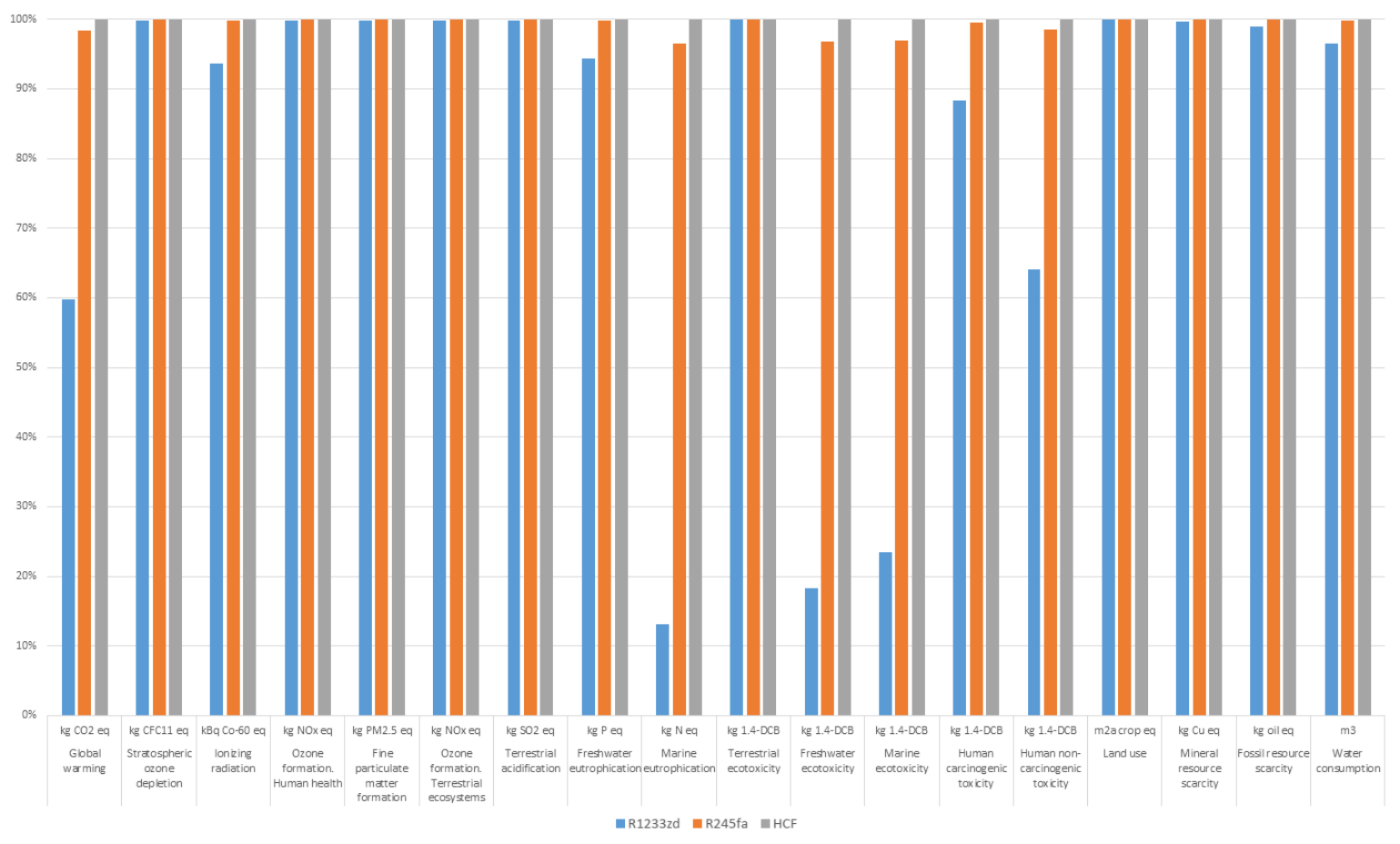

Figure 9. Comparisons of the life cycle impacts for three different organic fluids. Results are obtained with ReCiPe 2016-Midpoint (H) method.

These results are in agreement with Ref. [41], which studies a geothermal ORC plant. Obviously, the comparison between the authors and reference outcomes is not simple since a geothermal plant needs a lot of infrastructures, very impacting on the environment, which are not necessary when biomass is used. On the other hand, a geothermal unit does not require combustion and continuous 
biomass consumption which in turn, means continuous biomass cultivation and transportation to the site. In addition, the ORC lifetime estimation for the two plants is very different.

In any case, the improvement of the climate change impact obtained using R1233zd fluid instead of R245fa in the present analysis is about $60 \mathrm{~g} \mathrm{CO}_{2} / \mathrm{kWh}$ which is similar to the value obtained in Ref. [41].

In addition, also in Ref. [41] the analysis confirms that the other impact categories are marginally modified by the use of different fluids.

Lastly, the CED method shows that for each $\mathrm{kWh}$ of electricity, the system uses about $7.3 \mathrm{kWh}$ of biomass, but also about $0.24 \mathrm{kWh}$ of fossil fuels, mainly due to the need of Diesel for biomass transportation, chipping and harvesting.

\section{Conclusions}

Renewable energy sources and energy efficiency are considered the most useful ways to tackle climate change and shift towards a low-carbon economy.

To this purpose, economic supports have been established throughout the years and the main outcome is the widespread of renewable plants, while energy efficiency still lacking especially in the renewable energy sources field.

Among renewables, biomass and, in particular, solid biomass like woodchip, constitutes a valid option to generate electricity, heat or a combination of them due to high fuel supplies programmability and boilers efficiency.

In the energy efficiency sector, the organic Rankine cycle is a consolidate technology which guarantees good efficiency and high reliability.

Therefore, biomass boilers coupled with organic Rankine cycles are a viable option that guarantees to generate electricity and heat.

Despite biomass renewability and ORC unit capability of recovering the waste heat coming from biomass combustion products, it is mandatory to examine system environmental impact taking into account for the fuel supply chain and impacts on the environment caused by organic fluid losses linked to plant leakages.

To this purpose and by means of the lifecycle assessment method, the authors study the environmental impacts of a system composed by a biomass boiler and a $150 \mathrm{~kW}$ cogenerative ORC unit.

The analysis is not based on simulation results, but on data collected during five years of plant operation. This aspect is crucial when a life cycle approach is used.

Results show that the most impacting processes in terms of $\mathrm{CO}_{2}$ equivalent emissions are the ones related to biomass production and organic fluid leakages. They accounted for $71 \%$ and $19 \%$ of the total, respectively.

Therefore, being fluid release into the environment high impacting, a comparison among three fluids are also performed and presented.

The analysis reveals that adopting R1233zd instead of the hydrocarbons fluid actually mounted in the cycle guarantees an improvement in all the impact categories but especially in the climate change one.

It is also finally important to remark that the CED method shows that for each $\mathrm{kWh}$ of electricity, the system composed by a biomass boiler and an ORC uses about $7.3 \mathrm{kWh}$ of biomass and approximately $0.24 \mathrm{kWh}$ of fossil fuels because there is the need of Diesel fuel for biomass transportation, chipping and harvesting.

In future works, the analysis will be extended to different in-operation plants based on the same commercial ORC unit. This is fundamental to evaluate how different management strategies, for example related to the transport and the cultivation of biomass or to CHP mode, can affect the overall impact of the plant. 
Author Contributions: conceptualization, A.S. and A.B.; data curation, A.S. and A.B.; investigation, A.S. and A.B.; writing-original draft, A.B.; writing-review and editing, A.S. and A.B. All authors have read and agreed to the published version of the manuscript.

Funding: This research received no external funding.

Conflicts of Interest: Authors declare no conflict of interest.

\section{Nomenclature}

\begin{tabular}{|c|c|}
\hline 1.4-DCB & 1.4-DICHLOROBENZENE \\
\hline CFC11 & Trichlorofluoromethane \\
\hline $\mathrm{CHP}$ & Combined Heat and Power \\
\hline $\mathrm{CO}_{2}$ & Carbon Dioxide \\
\hline $\mathrm{Cu}$ & Copper \\
\hline eq & equivalent \\
\hline EU & European Union \\
\hline g & gramme \\
\hline GHG & Green House Gases \\
\hline GT & Gas Turbine \\
\hline GWP & Global Warming Potential \\
\hline $\mathrm{HCF}$ & hydrocarbons fluid \\
\hline ICE & Internal Combustion Engine \\
\hline kBq Co-60eq & kilobecquerels of cobalt- 60 equivalents \\
\hline $\mathrm{kg}$ & kilogramme \\
\hline LCA & Life Cycle Assessment \\
\hline $\mathrm{N}$ & Nitrogen \\
\hline $\mathrm{NO}_{x}$ & Nitrogen Oxide \\
\hline ODP & Ozone Depletion Potential \\
\hline ORC & Organic Rankine Cycle \\
\hline $\mathrm{P}$ & Phosphorus \\
\hline PM & Particulate Matter \\
\hline RES & Renewable Energy Sources \\
\hline $\mathrm{SO}_{2}$ & Sulphur Dioxide \\
\hline SRC & Steam Rankine Cycle \\
\hline WHRU & Waste Heat Recovery Unit \\
\hline
\end{tabular}

\section{References}

1. BP. BP Statistical Review of World Energy 2018; BP: London, UK, 2018.

2. International Energy Agency. World Energy Outlook 2018 Summary; Technical report; International Energy Agency: Paris, France, 2018. [CrossRef]

3. International Renewable Energy Agency (IRENA). Global Energy Transformation: A Roadmap to 2050; International Renewable Energy Agency: Abu Dhabi, UAE, 2018. [CrossRef]

4. European Parliament and Council of the European Union. Directive 2009/28/EC of the European Parliament and of the Council of 23 April 2009 on the Promotion of the Use of Energy from Renewable sources and Amending and Subsequently Repealing Directives 2001/77/EC and 2003/30/EC; European Commission: Brussels, Belgium, 2009.

5. European Council . 2030 Framework for Climate and Energy Policies; European Commission: Brussels, Belgium, 2014.

6. European Council. EU Roadmap 2050; European Commission: Brussels, Belgium, 2010.

7. Stoppato, A.; Benato, A.; Mirandola, A. Assessment of stresses and residual life of plant components in view of life-time extension of power plants. In Proceedings of the 25th International Conference on Efficiency, Cost, Optimization, Simulations and Environmental Impact of Energy Systems (ECOS 2012), Perugia, Italy, 26-29 June 2012.

8. Benato, A.; Stoppato, A.; Bracco, S. Combined cycle power plants: A comparison between two different dynamic models to evaluate transient behaviour and residual life. Energy Convers. Manag. 2014, 87, 1269-1280. [CrossRef] 
9. Benato, A.; Stoppato, A.; Mirandola, A. Dynamic behaviour analysis of a three pressure level heat recovery steam generator during transient operation. Energy 2015, 90, 1595-1605. [CrossRef]

10. Benato, A.; Stoppato, A. Pumped Thermal Electricity Storage: A technology overview. Therm. Sci. Eng. Prog. 2018, 6, 301-315. [CrossRef]

11. Benato, A.; Stoppato, A. Energy and cost analysis of an Air Cycle used as prime mover of a Thermal Electricity Storage. J. Energy Storage 2018, 17, 29-46. [CrossRef]

12. Benato, A.; Stoppato, A. Integrated Thermal Electricity Storage System: Energetic and cost performance. Energy Convers. Manag. 2019, 197, 111833. [CrossRef]

13. Benato, A.; Stoppato, A. Energy and Cost Analysis of a New Packed Bed Pumped Thermal Electricity Storage Unit. J. Energy Resour. Technol. Trans. ASME 2018. [CrossRef]

14. Benato, A.; Stoppato, A. Heat transfer fluid and material selection for an innovative Pumped Thermal Electricity Storage system. Energy 2018, 147, 155-168. [CrossRef]

15. Park, H.; Baldick, R. Integration of compressed air energy storage systems co-located with wind resources in the ERCOT transmission system. Int. J. Electr. Power Energy Syst. 2017, 90, 181-189. [CrossRef]

16. Benato, A. Performance and cost evaluation of an innovative Pumped Thermal Electricity Storage power system. Energy 2017, 138, 419-436. [CrossRef]

17. Benato, A.; Stoppato, A.; Mirandola, A. State-of-the-art and future development of sensible heat thermal electricity storage systems. Int. J. Heat Technol. 2017, 35, S244-S251. [CrossRef]

18. WBA. Global Bioenergy Statistics 2018; Technical Report; WBA: West Bromwich, UK, 2018.

19. Pereira, R.G.; Oliveira, C.D.; Oliveira, J.L.; Oliveira, P.C.P.; Fellows, C.E.; Piamba, O.E. Exhaust emissions and electric energy generation in a stationary engine using blends of diesel and soybean biodiesel. Renew. Energy 2007. [CrossRef]

20. Benato, A.; Macor, A. Italian Biogas Plants: Trend, Subsidies, Cost, Biogas Composition and Engine Emissions. Energies 2019, 12, 979. [CrossRef]

21. Chiaramonti, D.; Rizzo, A.M.; Spadi, A.; Prussi, M.; Riccio, G.; Martelli, F. Exhaust emissions from liquid fuel micro gas turbine fed with diesel oil, biodiesel and vegetable oil. Appl. Energy 2013. [CrossRef]

22. Benato, A.; Macor, A.; Rossetti, A. Biogas Engine Emissions: Standards and On-Site Measurements. Energy Procedia 2017, 126, 398-405. [CrossRef]

23. Nikpey Somehsaraei, H.; Mansouri Majoumerd, M.; Breuhaus, P.; Assadi, M. Performance analysis of a biogas-fueled micro gas turbine using a validated thermodynamic model. Appl. Therm. Eng. 2014. [CrossRef]

24. Benato, A.; Macor, A. Biogas Engine Waste Heat Recovery Using Organic Rankine Cycle. Energies 2017, 10, 327. [CrossRef]

25. Macor, A.; Benato, A. Experimental Measurements and Damage Assessment on Human Health. Energies 2020, 13, 1044. [CrossRef]

26. Vélez, F.; Segovia, J.J.; Martin, M.C.; Antolin, G.; Chejne, F.; Quijano, A. A technical, economical and market review of organic Rankine cycles for the conversion of low-grade heat for power generation. Renew. Sustain. Energy Rev. 2012, 16, 4175-4189. [CrossRef]

27. Benato, A.; Stoppato, A.; Mirandola, A. Renewable Energy Conversion and Waste Heat Recovery Using Organic Rankine Cycles. In Renewable Energy Systems; Kale, S.A., Ed.; Nova Science Publishers: Hauppauge, NY, USA, 2016; Chapter 11.

28. Bianchi, M.; De Pascale, A. Bottoming cycles for electric energy generation: Parametric investigation of available and innovative solutions for the exploitation of low and medium temperature heat sources. Appl. Energy 2011, 88, 1500-1509. [CrossRef]

29. Pezzuolo, A.; Benato, A.; Stoppato, A.; Mirandola, A. The ORC-PD: A versatile tool for fluid selection and Organic Rankine Cycle unit design. Energy 2016, 102, 605-620. [CrossRef]

30. Benato, A. Improving the efficiency of a cataphoresis oven with a cogenerative organic Rankine cycle unit. Therm. Sci. Eng. Prog. 2018, 5, 182-194. [CrossRef]

31. Pezzuolo, A.; Benato, A.; Stoppato, A.; Mirandola, A. Recovering gas turbine high-temperature exhaust heat using organic Rankine cycle with mixture as working fluid. In Proceedings of the 29th International Conference on Efficiency, Cost, Optimization, Simulations and Environmental Impact of Energy Systems (ECOS 2016), Portoroz, Slovenia 19-26 June 2016. 
32. Campana, F.; Bianchi, M.; Branchini, L.; De Pascale, A.; Petto, A.; Baresi, M.; Fermi, A.; Rossetti, N.; Vescovo, R. ORC waste heat recovery in European energy intensive industries: Energy and GHG savings. Energy Convers. Manag. 2013, 76, 244-252. [CrossRef]

33. Branchini, L.; De Pascale, A.; Peretto, A. Systematic comparison of $\{\mathrm{ORC}\}$ configurations by means of comprehensive performance indexes. Appl. Therm. Eng. 2013, 61, 129-140. [CrossRef]

34. Cavazzini, G.; Bari, S.; Pavesi, G.; Ardizzon, G. A multi-fluid PSO-based algorithm for the search of the best performance of sub-critical Organic Rankine Cycles. Energy 2017. [CrossRef]

35. Benato, A.; Cavazzini, G.; Bari, S.; Ardizzon, G. ORC pump efficiency estimation and real behaviour under different working fluids. In Proceedings of the 32nd International Conference on Efficiency, Cost, Optimization, Simulation and Environmental Impact of Energy Systems (ECOS 2019), Wrocław, Poland, 23-28 June 2019.

36. Ancona, M.A.; Bianchi, M.; Branchini, L.; De Pascale, A.; Melino, F.; Orlandini, V.; Ottaviano, S.; Peretto, A.; Pinelli, M.; Spina, P.R.; et al. A Micro-ORC Energy System: Preliminary Performance and Test Bench Development. Energy Procedia 2016. [CrossRef]

37. Ancona, M.A.; Bianchi, M.; Branchini, L.; Pascale, A.; Melino, F.; Ottaviano, S.; Peretto, A.; Scarponi, L.B. Heat recovery from a liquefied natural gas production process by means of an organic rankine cycle. In Proceedings of the ASME Turbo Expo, Lillestrøm, Norway, 11 June 2018. [CrossRef]

38. ISO. 14040: Environmental Management-Life Cycle Assessment-Principles and Framework; International Organization for Standardization: Geneva, Switzerland, 2006.

39. Stougie, L.; Tsalidis, G.A.; van der Kooi, H.J.; Korevaar, G. Environmental and exergetic sustainability assessment of power generation from biomass. Renew. Energy 2018. [CrossRef]

40. Walsh, C.; Thornley, P. The environmental impact and economic feasibility of introducing an organic Rankine cycle to recover low grade heat during the production of metallurgical coke. J. Clean. Prod. 2012. [CrossRef]

41. Liu, C.; He, C.; Gao, H.; Xie, H.; Li, Y.; Wu, S.; Xu, J. The environmental impact of organic Rankine cycle for waste heat recovery through life-cycle assessment. Energy 2013. [CrossRef]

42. Heberle, F.; Schifflechner, C.; Brüggemann, D. Life cycle assessment of Organic Rankine Cycles for geothermal power generation considering low-GWP working fluids. Geothermics 2016. [CrossRef]

43. Lin, Y.P.; Wang, W.H.; Pan, S.Y.; Ho, C.C.; Hou, C.J.; Chiang, P.C. Environmental impacts and benefits of organic Rankine cycle power generation technology and wood pellet fuel exemplified by electric arc furnace steel industry. Appl. Energy 2016. [CrossRef]

44. Uusitalo, A.; Uusitalo, V.; Grönman, A.; Luoranen, M.; Jaatinen-Värri, A. Greenhouse gas reduction potential by producing electricity from biogas engine waste heat using organic Rankine cycle. J. Clean. Prod. 2016. [CrossRef]

45. Sedpho, S.; Sampattagul, S.; Chaiyat, N.; Gheewala, S.H. Conventional and exergetic life cycle assessment of organic rankine cycle implementation to municipal waste management: The case study of Mae Hong Son (Thailand). Int. J. Life Cycle Assess. 2017. [CrossRef]

46. Monteleone, B.; Chiesa, M.; Marzuoli, R.; Verma, V.K.; Schwarz, M.; Carlon, E.; Schmidl, C.; Ballarin Denti, A. Life cycle analysis of small scale pellet boilers characterized by high efficiency and low emissions. Appl. Energy 2015. [CrossRef]

47. Singh, P.; Gundimeda, H.; Stucki, M. Environmental footprint of cooking fuels: A life cycle assessment of ten fuel sources used in Indian households. Int. J. Life Cycle Assess. 2014. [CrossRef]

48. Boschiero, M.; Kelderer, M.; Schmitt, A.O.; Andreotti, C.; Zerbe, S. Influence of agricultural residues interpretation and allocation procedures on the environmental performance of bioelectricity production-A case study on woodchips from apple orchards. Appl. Energy 2015. [CrossRef]

49. Stoppato, A. Life cycle assessment of photovoltaic electricity generation. Energy 2008. [CrossRef]

50. Fantinato, D.; Stoppato, A.; Benato, A. LCA analysis of a low-energy residential building. In Proceedings of the 32nd International Conference on Efficiency, Cost, Optimization, Simulation and Environmental Impact of Energy Systems (ECOS 2019), Wrocław, Poland, 23-28 June 2019; pp. 3153-3165.

51. Toscani, A.; Stoppato, A.; Benato, A. LCA of a concert: Evaluation of the Carbon footprint and of Cumulative energy demand. In Proceedings of the 32nd International Conference on Efficiency, Cost, Optimization, Simulation and Environmental Impact of Energy Systems (ECOS 2019), Wrocław, Poland, 23-28 June 2019; pp. 3203-3213.

52. Préconsultants. SimaPro 9.0. Available online: https://simapro.com/ (accessed on 8 April 2020). 
53. Laleman, R.; Albrecht, J.; Dewulf, J. Life cycle analysis to estimate the environmental impact of residential photovoltaic systems in regions with a low solar irradiation. Renew. Sustain. Energy Rev. 2011, 15, $267-281$. [CrossRef]

54. Hung, T.C.; Wang, S.K.; Kuo, C.H.; Pei, B.S.; Tsai, K.F. A study of organic working fluids on system efficiency of an ORC using low-grade energy sources. Energy 2010. [CrossRef]

55. Qiu, G.; Shao, Y.; Li, J.; Liu, H.; Riffat, S.B. Experimental investigation of a biomass-fired \{ORC\}-based micro- $\{\mathrm{CHP}\}$ for domestic applications. Fuel 2012, 96, 374-382. [CrossRef]

56. IPCC. Revised Supplementary Methods and Good Practice Guidance Arising from the Kyoto Protocol, Intergovernmental Panel on Climate Change; Technical Report; IPCC: Geneva, Switzerland, 2013.

57. Huijbregts, M.; Steinmann, Z.J.N.; Elshout, P.M.F.M.; Stam, G.; Verones, F.; Vieira, M.D.M.; Zijp, M.; van Zelm, R. ReCiPe 2016; National Institute for Public Health and the Environment: Bilthoven, The Netherlands, 2016. [CrossRef]

58. Frischknecht, R.; Wyss, F.; Büsser Knöpfel, S.; Lützkendorf, T.; Balouktsi, M. Cumulative energy demand in LCA: the energy harvested approach. Int. J. Life Cycle Assess. 2015. [CrossRef]

59. Schmitz, S.; Dawson, B.; Spannagle, M.; Thomson, F.; Koch, J.; Eaton, R. The Greenhouse Gas Protocol—A Corporate Accounting and Reporting Standard; Revised ed.; The GHG Protocol Corporate Accounting and Reporting Standard; World Resources Institute and World Business Council for Sustainable Development: Washington, DC, USA, 2001.

60. Istituto Superiore per la Protezione e la Ricerca Ambientale. Fattori di emissione per la produzione ed il consumo di energia elettrica in Italia (Emission Factors for Production and Consumption of electricity); Technical Report; 2019. Available online: http:/ / www.sinanet.isprambiente.it/it/sia-ispra/serie-storiche-emissioni/ (accessed on 8 April 2020).

61. Stougie, L.; Giustozzi, N.; van der Kooi, H.; Stoppato, A. Environmental, economic and exergetic sustainability assessment of power generation from fossil and renewable energy sources. Int. J. Energy Res. 2018. [CrossRef]

(C) 2020 by the authors. Licensee MDPI, Basel, Switzerland. This article is an open access article distributed under the terms and conditions of the Creative Commons Attribution (CC BY) license (http://creativecommons.org/licenses/by/4.0/). 